\title{
CYP17 genetic polymorphism, breast cancer, and breast cancer risk factors
}

\author{
Christine B Ambrosone ${ }^{1}$, Kirsten B Moysich ${ }^{1}$, Helena Furberg ${ }^{2}$, Jo L Freudenheim ${ }^{3}$, \\ Elise D Bowman ${ }^{4}$, Sabrina Ahmed ${ }^{4}$, Saxon Graham ${ }^{3}$, John E Vena ${ }^{3}$ and Peter G Shields ${ }^{5}$
}

${ }^{1}$ Department of Epidemiology, Roswell Park Cancer Institute, Buffalo, New York, USA

2Derald H Ruttenberg Cancer Center, Mount Sinai School of Medicine, New York, USA

${ }^{3}$ Department of Social and Preventive Medicine, University at Buffalo, Buffalo, New York, USA

${ }^{4}$ Laboratory for Human Carcinogenesis, National Cancer Institute, Bethesda, Maryland, USA

${ }^{5}$ Division of Cancer Genetics and Epidemiology, Lombardi Cancer Center, Georgetown University Medical Center, Washington, DC, USA

Corresponding author: Christine B Ambrosone (e-mail: christine.ambrosone@roswellpark.org)

Received: 21 August 2002 Revisions received: 30 October 2002 Accepted: 17 December 2002 Published: 29 January 2003

Breast Cancer Res 2003, 5:R45-R51 (DOI 10.1186/bcr570)

(c) 2003 Ambrosone et al., licensee BioMed Central Ltd (Print ISSN 1465-5411; Online ISSN 1465-542X). This is an Open Access article: verbatim copying and redistribution of this article are permitted in all media for any non-commercial purpose, provided this notice is preserved along with the article's original URL.

\begin{abstract}
Background: Findings from previous studies regarding the association between the CYP17 genotype and breast cancer are inconsistent. We investigated the role of the MspAl genetic polymorphism in the $5^{\prime}$ region of CYP17 on risk of breast cancer and as a modifier of reproductive risk factors.

Methods: Questionnaire and genotyping data were obtained from a population-based, case-control study of premenopausal $(n=182)$ and postmenopausal $(n=214)$ European-American Caucasian women in western New York. Cases and controls were frequency matched by age and by county of residence. Odds ratios and $95 \%$ confidence intervals were used to estimate relative risks.

Results: The CYP17 genotype was not associated with breast cancer risk; however, controls with the A2/A2 genotype

(associated with higher estrogens) had earlier menarche and earlier first full-term pregnancy. Premenopausal women with A1/A1 genotypes, but not with A2 alleles, were at significantly decreased risk with late age at menarche (odds ratio $=0.37$, $95 \%$ confidence interval $=0.14-0.99$ ), and at increased risk with late age at first full-term pregnancy (odds ratio $=4.30$, $95 \%$ confidence interval $=1.46-12.67$ ) and with use of oral contraceptives (odds ratio $=3.24,95 \%$ confidence interval=1.08-9.73). Associations were weaker among postmenopausal women.

Conclusion: These results suggest that the effects of factors that may alter breast cancer risk through a hormonal mechanism may be less important among premenopausal women with putative higher lifetime exposures to circulating estrogens related to the CYP17 A2 allele.
\end{abstract}

Keywords: breast neoplasms, cytochrome $\mathrm{P} 450 \mathrm{c} 17 \alpha$, epidemiology, genetic polymorphism

\section{Introduction}

A number of studies have evaluated possible associations between a polymorphism in the cytochrome $P 450 \mathrm{c} 17 \alpha$ (CYP17) gene and breast cancer risk [1-16]. Cytochrome P450c17 $\alpha$ functions at key branch points in human steroidogenesis, catalyzing the ovarian and adrenal biosynthesis pathways for androstenedione, the immediate precursor of testosterone [17]. Three polymorphisms have been described in this gene: a $C \rightarrow T$ transition at nucleotide 5471 in intron 6 [18], a $G \rightarrow A$ transition at nucleotide 47 in the $5^{\prime}$-untranslated region promoter [19], and a thymidine substitution for cytosine at nucleotide 27 in the $5^{\prime}$-untranslated region promoter that creates a MspAl recognition site [20].

The MspAl polymorphism gives rise to three genotypes (A1/A1, A1/A2, and A2/A2). Although it was hypothesized that the polymorphism (A2 allele) could result in an additional Sp1 binding site with enhanced promoter activity and an increased rate of transcription [1], this was not 
found in experimental studies $[20,21]$. Nonetheless, two studies found that both premenopausal and postmenopausal women with the variant A2 allele had higher levels of circulating estrogens than those with common alleles, indicating that the polymorphism may be in linkage disequilibrium with another functional polymorphism or that it may affect hormone levels through some other mechanism [4,22].

Effects of the variant CYP17 genotype on risk have been investigated in a number of studies, with some corroborative results and some conflicting results. In a multiethnic cohort, while breast cancer risk was not significantly increased for women with the A2 allele [1], the A2 allele did confer more than a twofold increase in risk among those with advanced disease. Furthermore, late age at menarche was protective only among women who were homozygous for the A1 allele. The findings regarding age at menarche were confirmed in three other studies [2,4,9] and in a recent meta-analysis involving 4227 cases and 4730 controls [16]. These studies did not find that the CYP17 genotype was associated with risk of breast cancer, even when stratifying by stage of disease $[4,9,16]$.

Feigelson et al. [23] recently reported that women with $\mathrm{A} 2$ alleles were less likely than those with $A 1$ alleles to use hormone replacement therapy, presumably because of fewer menopausal symptoms due to higher circulating estrogens. It is clear that hormonal milieu differs for premenopausal women and postmenopausal women, and there is evidence that risk factors for disease diagnosed among the two groups of women may also differ, particularly those related to hormonal factors [24].

The majority of previous studies did not evaluate associations separately by menopausal status, particularly for effect modification by CYP17 on relationships between breast cancer and other risk factors. In the present study, we evaluated, separately for premenopausal and postmenopausal women, whether the CYP17 polymorphism was independently related to breast cancer risk or could possibly act through modification of other breast cancer risk factors.

\section{Materials and methods Population}

These research data were collected in an earlier case-control study (1986-1991) of 617 premenopausal and 933 postmenopausal Caucasian women in western New York. The detailed methods have been reported elsewhere [25-27].

The protocol for the present study was reviewed by the Institutional Review Board of the State University of New York at Buffalo and by all of the participating hospitals. Informed consent was received from all participants for diagnosed with incident, primary, histologically confirmed breast cancer were identified at all major hospitals in Erie and Niagara counties. They were frequency matched by age and county of residence with controls randomly selected from the New York State Motor Vehicle lists ( $<65$ years) and the Health Care Finance Administration rolls ( $>65$ years). Interview data included medical, reproductive, dietary, and lifestyle histories. The majority of women were born in the United States, and all women reported country of birth of their parents to be in Western Europe or, to a lesser degree, in Eastern Europe.

Women were considered postmenopausal if they were younger than age 50 years and had natural menopause, had bilateral oophorectomy or had irradiation to the ovaries. Women aged 50 years and older were considered postmenopausal if they had ceased menstruation. At the end of the interview, women were asked to provide a blood specimen; $45 \%$ of premenopausal women and $63 \%$ of postmenopausal women agreed. Among premenopausal women, there were no significant differences in socioeconomic, hormonal, reproductive, or dietary factors between those who gave blood and those who refused. Among postmenopausal women, controls who gave a blood specimen had a greater mean number of pregnancies (3.5 versus $2.9, P<0.01$ ) than those who declined. There were no other significant differences between the groups.

\section{Laboratory analysis}

DNA was purified by standard phenol/chloroform extraction followed by ethanol precipitation from frozen blood clots. PCR conditions were based on those of Carey et al. [19].

Briefly, genomic DNA (50 ng) was amplified using $50 \mathrm{pmol}$ primers (5'-CAT TCG CAC TCT GGA GTC-3' and 5'-AGG CTC TTG GGG TAC TTG-3') in GeneAmp PCR buffer $(50 \mathrm{mM} \mathrm{KCl}, 10 \mathrm{mM}$ Tris-HCl, pH 8.3, 0.001\% [w/v] gelatin, $1.5 \mathrm{mM} \mathrm{MgCl}_{2}$; Perkin Elmer, Norwalk, CT, USA), and Amplitaq DNA polymerase (2.5 U; Perkin Elmer) with 2'-deoxynucleoside-3'-triphosphates $(1.87 \mathrm{mM}$; Pharmacia, Piscataway, NJ, USA) in a $50 \mu \mathrm{l}$ reaction volume. The PCR reaction had an initial melting temperature of $94^{\circ} \mathrm{C}(5 \mathrm{~min})$ followed by 30 cycles of melting $\left(94^{\circ} \mathrm{C}, 1 \mathrm{~min}\right)$, annealing $\left(56^{\circ} \mathrm{C}, 1 \mathrm{~min}\right)$, and extension $\left(72^{\circ} \mathrm{C}, 1 \mathrm{~min}\right)$. An extension period of $7 \mathrm{~min}$ at $72^{\circ} \mathrm{C}$ followed the final cycle. The resulting product (459 bp) was subjected to MspAl digest (New England Biolabs, Beverly, MA, USA) according to the manufacturer's directions. Gel electrophoresis (2.2\% agarose; Gibco BRL, Gaithersburg, MD, USA) of the resulting fragments revealed either the A1 homozygote ( $459 \mathrm{bp})$, the A2 homozygote (335 and $124 \mathrm{bp}$ ), or the A1/A2 heterozygote (459, 335, and $124 \mathrm{bp})$.

Results of genotyping for the study were read from the gel by two independent investigators, and at least $20 \%$ of the 
samples were repeated for quality control. The assay was validated by confirming polymorphic Mendelian inheritance patterns in seven human family cell lines $(n=134)$, each encompassing three generations (data not shown; NIGMS Human Genetic Mutant Cell Repository, Coriell Institute, Camden, NJ, USA).

\section{Statistical analysis}

Tests for Hardy-Weinberg equilibrium among controls were conducted using observed genotype frequencies and a $\chi^{2}$ test with one degree of freedom. To evaluate the role of CYP17 on breast cancer risk through mediating mechanisms, we first assessed differences in age at menarche, age at first full-term pregnancy, difficulty in becoming pregnant, and use of hormone replacement therapy and oral contraceptives among controls according to the CYP17 genotype.

Data on hormone replacement use were only available for women who were postmenopausal, and few women beyond menopause had a history of oral contraceptive use, so only premenopausal women were included for those analyses. Odds ratios and 95\% confidence intervals were calculated using unconditional logistic regression to evaluate associations between CYP17 genotypes and breast cancer risk separately for premenopausal and postmenopausal women. The odds ratios were adjusted for age, education, age at menarche, age at first pregnancy, reported family history of breast cancer, body mass index, history of benign breast disease, and age at menopause for postmenopausal women.

Associations between hormonal/reproductive factors and breast cancer were further calculated within genotype strata. We performed tests for interaction by computing the crossproduct of the independent variables (CYP17 and reproductive factors whose effects on risk varied by genotype) and including it in a regression model with its components entered separately.

\section{Results}

Data in the present study were available for 182 premenopausal and 214 postmenopausal women. The mean age among premenopausal women was 47 years, and the average age of postmenopausal women was 63 years. We evaluated information on the participant's country of origin and their parent's country of origin. In this fairly homogeneous population, all of the women were of European or Eastern European decent. A $\chi^{2}$ test of observed versus expected genotype frequencies for CYP17 among premenopausal women suggested a slight deviation from Hardy-Weinberg equilibrium. However, this difference was not statistically significant $(P=0.08)$. The genotype frequencies for postmenopausal women followed Hardy-Weinberg equilibrium $(P=0.65)$.
Hormonally related factors appeared to vary by CYP17 genotype (Table 1). Among both premenopausal and postmenopausal women, those with at least one A2 allele were more likely than women with the A1/A1 genotype to experience early menarche, although differences were not statistically significant. There were also slight differences in age at menopause, with a somewhat later average age at menopause for women with either the A1/A2 or A2/A2 genotypes. Interestingly, postmenopausal women with at least one A2 allele were also less likely to experience difficulty in becoming pregnant and, correspondingly, tended to have children at an earlier age. Contrary to findings by Feigelson et al. [23], the CYP17 genotype did not influence the use of hormone replacement therapy or oral contraceptives in the present data.

Neither homozygosity nor heterozygosity for the A2 variant was associated with increased breast cancer risk (Table 2). In fact, there appeared to be inverse associations between the A2 allele and risk, particularly among postmenopausal women, in both unadjusted models and those models adjusted for breast cancer risk factors. Because there were few differences in relationships for those with A1/A2 and A2/A2 genotypes, these categories were collapsed and the associations evaluated between genotype and other breast cancer risk factors.

Associations between breast cancer and hormonal risk factors by CYP17 genotype are presented in Table 3. For premenopausal women, late age at menarche was significantly protective only among women with A1/A1 alleles (odds ratio $=0.37 ; 95 \%$ confidence interval $=0.14-0.99$ ). This effect was not seen among postmenopausal women. Differences in risk were also noted for other factors. Late age at first full-term pregnancy significantly increased risk among premenopausal women only for those with the A1/A1 genotype. Risk was also elevated among these allele carriers if they reported use of oral contraceptives and difficulty becoming pregnant. For postmenopausal women, it was women with A2 alleles who were most at risk of breast cancer with late age at first full-term pregnancy and with difficulty becoming pregnant. While effects of age at menarche, age at first full-term pregnancy, and oral contraceptive use were only significantly notable among premenopausal women with A1 alleles, interactions were not statistically significant (data not shown).

\section{Discussion}

We found in the present study that while the CYP17 MspAl genetic polymorphism did not increase breast cancer risk, it appears to modify the associations between hormonal and reproductive factors and breast cancer. Interestingly, women with A2 alleles, those associated with higher estrogen levels in both premenopausal and postmenopausal women, were more likely to share char- 
Table 1

Distribution of breast cancer risk factors among controls in relation to the CYP17 genotype: Western New York Breast Cancer Study

\begin{tabular}{|c|c|c|c|c|}
\hline \multirow[b]{2}{*}{ CYP17 genotype } & \multicolumn{2}{|c|}{ Premenopausal $(n=86)$} & \multicolumn{2}{|c|}{ Postmenopausal ( $n=102)$} \\
\hline & $\mathrm{A} 1 / \mathrm{A} 1$ & $\mathrm{~A} 1 / \mathrm{A} 2$ and $\mathrm{A} 2 / \mathrm{A} 2$ & $\mathrm{~A} 1 / \mathrm{A} 1$ & $\mathrm{~A} 1 / \mathrm{A} 2$ and $\mathrm{A} 2 / \mathrm{A} 2$ \\
\hline \multicolumn{5}{|l|}{ Age at menarche } \\
\hline$<13$ years & $15(31)$ & $18(49)$ & $18(38)$ & $25(46)$ \\
\hline$\geq 13$ years & $33(69)$ & $20(51)$ & $29(62)$ & $30(54)$ \\
\hline \multicolumn{5}{|c|}{ Difficulty getting pregnant } \\
\hline No & $38(79)$ & $29(76)$ & $32(68)^{*}$ & $47(86)^{\star}$ \\
\hline Yes & $10(21)$ & $9(24)$ & $11(23)$ & $8(14)$ \\
\hline \multicolumn{5}{|l|}{ Age at first birth } \\
\hline$<25$ years & $38(79)$ & $28(74)$ & $21(45)^{\star}$ & $40(73)^{\star}$ \\
\hline$\geq 25$ years & $10(21)$ & $10(26)$ & $26(55)$ & $15(27)$ \\
\hline \multicolumn{5}{|c|}{ Ever use oral contraceptives } \\
\hline No & $26(54)$ & $19(50)$ & & \\
\hline Yes & $22(46)$ & $19(50)$ & & \\
\hline \multicolumn{5}{|c|}{ Family history of breast cancer } \\
\hline No & $45(94)$ & $35(92)$ & $43(91)$ & $50(91)$ \\
\hline Yes & $3(6)$ & $3(8)$ & $4(9)$ & $5(9)$ \\
\hline \multicolumn{5}{|l|}{ Age at menopause } \\
\hline$<48$ years & & & $29(62)$ & $29(53)$ \\
\hline$\geq 48$ years & & & $18(38)$ & $26(47)$ \\
\hline \multicolumn{5}{|c|}{ Ever use hormone replacement therapy } \\
\hline No & & & $32(68)$ & $39(71)$ \\
\hline Yes & & & $15(32)$ & $16(29)$ \\
\hline
\end{tabular}

Data presented as $n(\%) .{ }^{*}$ Statistically significant $(P<0.05)$.

Table 2

Associations between CYP17 genetic polymorphisms and breast cancer by menopausal status: Western New York Breast Cancer Study

Crude odds ratio Adjusted odds ratio

Case $(n[\%]) \quad$ Control $(n[\%]) \quad(95 \% \mathrm{Cl}) \quad(95 \% \mathrm{Cl})^{\mathrm{a}}$

Premenopausal $(n=182)$

$\begin{array}{lcccr}\text { A1/A1 } & 58(61) & 48(56) & 1.00 & 1.00 \\ \text { A1/A2 } & 31(32) & 28(33) & 0.92(0.48-1.73) & 0.85(0.44-1.63) \\ \text { A2/A2 } & 7(7) & 10(11) & 0.58(0.21-1.64) & 0.56(0.20-1.62)\end{array}$

Postmenopausal $(n=213)$

$\begin{array}{lcccr}\text { A1/A1 } & 51(46) & 47(46) & 1.00 & 1.00 \\ \text { A1/A2 } & 52(47) & 43(42) & 1.10(0.63-1.90) & 0.97(0.45-2.20) \\ \text { A2/A2 } & 8(7) & 12(12) & 0.60(0.23-1.60) & 0.45(0.13-1.60)\end{array}$

a Adjusted for age, education, family history of breast cancer, body mass index, and history of benign breast disease (and age at menopause in 
Relationships between breast cancer and putative risk factors by CYP17 genotype: Western New York Breast Cancer Study

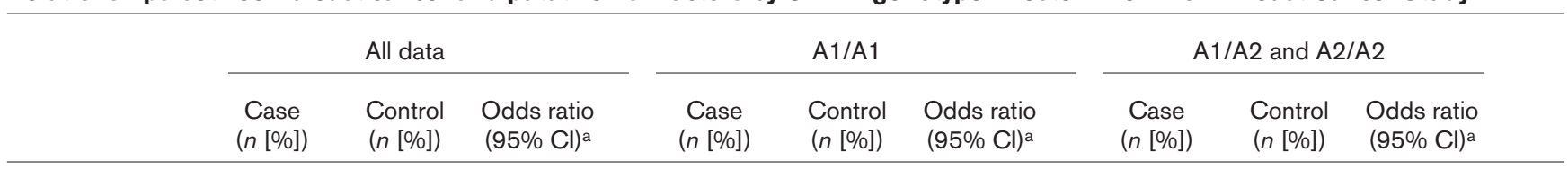

\section{Premenopausal}

Age at menarche

\begin{tabular}{|c|c|c|c|c|c|c|c|c|c|}
\hline$<13$ years & $47(50)$ & 33 (39) & 1.00 & $30(52)$ & $15(31)$ & 1.00 & $17(46)$ & $18(49)$ & 1.00 \\
\hline$\geq 13$ years & $48(51)$ & $52(61)$ & $\begin{array}{c}0.55 \\
(0.27-1.10)\end{array}$ & $28(48)$ & 33 (69) & $\begin{array}{c}0.37 \\
(0.14-0.99)\end{array}$ & $20(54)$ & $19(51)$ & $\begin{array}{c}0.84 \\
(0.27-2.61)\end{array}$ \\
\hline
\end{tabular}

Age at first birth

$\begin{array}{cccc}<25 \text { years } & 55(57) & 66(77) & 1.00 \\ \geq 25 \text { years } & 41(43) & 20(23) & 2.69 \\ & & & (1.34-5.39)\end{array}$

$\begin{array}{ccc}34(59) & 38(79) & 1.00 \\ 24(41) & 10(21) & 4.30 \\ & & (1.46-12.67)\end{array}$

$\begin{array}{ccc}21(55) & 28(74) & 1.00 \\ 17(45) & 10(26) & 2.13 \\ & & (0.76-6.02)\end{array}$

Difficulty getting pregnant

$\begin{array}{llcc}\text { No } & 82(79) & 79(81) & 1.00 \\ \text { Yes } & 22(21) & 19(19) & 0.97 \\ & & & (0.44-2.14)\end{array}$

$\begin{array}{ccc}40(71) & 38(79) & 1.00 \\ 16(29) & 10(21) & 2.23 \\ & & (0.69-7.24)\end{array}$

$$
\begin{array}{rrr}
33(89) & 29(76) & 1.00 \\
4(11) & 9(24) & 0.38
\end{array}
$$

Ever use oral contraceptives

$\begin{array}{lccc}\text { No } & 44(46) & 45(52) & 1.00 \\ \text { Yes } & 52(54) & 41(48) & 1.77 \\ & & & (0.84-3.74)\end{array}$

$\begin{array}{ccc}24(41) & 26(54) & 1.00 \\ 34(59) & 22(46) & 3.24 \\ & & (1.08-9.73)\end{array}$

$\begin{array}{ccc}20(53) & 19(50) & 1.00 \\ 18(47) & 19(50) & 0.67 \\ & & (0.20-2.26)\end{array}$

\section{Postmenopausal}

Age at menarche

$\begin{array}{cccc}<13 \text { years } & 56(50) & 43(42) & 1.00 \\ \geq 13 \text { years } & 56(50) & 59(58) & 0.78 \\ & & & (0.42-1.48)\end{array}$

$\begin{array}{ccc}25(48) & 18(38) & 1.00 \\ 27(52) & 29(62) & 0.72 \\ & & (0.27-1.91)\end{array}$

$$
\begin{array}{lll}
31(52) & 25(46) & 1.00 \\
29(48) & 30(55) & 0.80
\end{array}
$$

Age at first birth

$$
\begin{aligned}
& <25 \text { years } \\
& \geq 25 \text { years }
\end{aligned}
$$$$
60(54)
$$$$
61(60)
$$$$
1.00
$$$$
51 \text { (46) }
$$$$
41 \text { (40) }
$$$$
1.52
$$$$
\text { (0.83-2.77) }
$$

$$
\begin{array}{ccc}
29(57) & 21(48) & 1.00 \\
22(43) & 26(55) & 0.68 \\
& & (0.27-1.68)
\end{array}
$$

$$
\begin{array}{lll}
31(52) & 40(73) & 1.00 \\
29(48) & 15(27) & 2.90
\end{array}
$$

Difficulty getting pregnant

$$
\begin{array}{llcc}
\text { No } & 82(79) & 79(81) & 1.00 \\
\text { Yes } & 22(21) & 19(19) & 1.19 \\
& & & (0.58-2.41)
\end{array}
$$

$$
\begin{array}{ccc}
42(86) & 32(74) & 1.00 \\
7(14) & 11(26) & 0.47 \\
& & (0.14-1.50)
\end{array}
$$

$$
\begin{array}{ccc}
40(73) & 47(85) & 1.00 \\
15(27) & 8(15) & 2.59 \\
& & (0.91-7.38)
\end{array}
$$

Ever use hormone replacement therapy

$$
\begin{array}{lccc}
\text { No } & 89(80) & 71(70) & 1.00 \\
\text { Yes } & 23(20) & 31(30) & 0.94 \\
& & & (0.31-2.78)
\end{array}
$$

$$
\begin{array}{ccc}
40(77) & 32(68) & 1.00 \\
12(23) & 15(32) & 0.80 \\
& & (0.14-4.52)
\end{array}
$$

$$
\begin{array}{ccc}
49(82) & 39(71) & 1.00 \\
11(18) & 16(29) & 0.98 \\
& & (0.23-4.26)
\end{array}
$$

Age at menopause

$$
\begin{array}{lccc}
<48 \text { years } & 58(47) & 58(57) & 1.00 \\
\geq 48 \text { years } & 58(52) & 44(43) & 1.60 \\
& & & (0.91-2.84)
\end{array}
$$

$\begin{array}{ccc}24(47) & 29(62) & 1.00 \\ 27(53) & 18(38) & 1.98 \\ & & (0.84-4.68)\end{array}$

$\begin{array}{lcc}29(48) & 29(53) & 1.00 \\ 31(52) & 26(47) & 1.36 \\ & & (0.61-3.06)\end{array}$

a Adjusted for other factors in the table as well as age, education, family history of breast cancer, history of benign breast disease, and body mass index. $\mathrm{Cl}$, confidence interval. 
acteristics associated with greater fertility. They were more likely to have an earlier age at menarche, less difficulty becoming pregnant, an earlier age at first full-term pregnancy, and later age at menopause.

In accordance with previous studies $[4,9,12,16]$, later age at menarche was protective against breast cancer only among women homozygous for the A1 allele, although we noted this association only in premenopausal women. Furthermore, late age at first full-term pregnancy and oral contraceptive use increased risk only among premenopausal women homozygous for $\mathrm{A} 1$ alleles. Relationships were not as notable among postmenopausal women, although late age at first birth increased risk only among women with $\mathrm{A} 2$ alleles. These apparent discrepancies by menopausal status, although they may be due to chance, could reflect differences in the nature of premenopausal and postmenopausal breast cancer etiology, particularly in relation to steroid hormones.

The initial report of increased risk of breast cancer and modification of other risk factors by variability in CYP17 was promising for breast cancer research [1]. Steroid hormones clearly play a large role in breast cancer etiology, and identification of risk associated with genetic differences in their biosynthesis and metabolism could greatly elucidate mechanistic pathways and make inroads towards prevention for public health. However, this report was followed by a number of studies that did not corroborate those early results. As more studies have been conducted, relationships between the CYP17 genotype and breast cancer risk have become clearer, particularly through the repeated findings of modification of risk through other reproductive factors. Because two studies have noted higher estrogen levels among women with A2 alleles [4,23], it is possible that women with these genotypes have more lifetime exposure to circulating steroid hormones that is not abrogated by later age at menarche or by earlier age at first full-term pregnancy. Oral contraceptive use may similarly only impact risk in an environment of lower estrogens.

Experimental studies $[21,22]$ have shown that the CYP17 polymorphism in the $5^{\prime}$-flanking region of the gene does not influence binding to Sp1, as previously conjectured $[1,20]$. Nonetheless, studies in both premenopausal women and postmenopausal women have found that those with A2 alleles have higher circulating levels of steroid hormones. Thus, while the mechanism whereby the CYP17 polymorphism increases serum hormones levels has not been identified, it is probable that there are either effects that have not yet been elucidated or that the site is in linkage disequilibrium with another polymorphism that alters the function of the CYP17 enzyme.

Results from this study may be impacted by a number of
While we had data on 395 women, stratification by menopausal status and additional stratification by CYP17 genotype to evaluate differential effects of breast cancer risk factors resulted in small data points in some cells, and therefore results are interpreted cautiously. Nonetheless, results support findings from a number of studies and are consistent with findings from the two largest studies to date: those from the Nurses' Health Study [4] and the study of breast cancer in Finland [9]. In addition, our findings are in accordance with those of a meta-analysis of 15 case-control studies [16].

Furthermore, genotype frequencies among premenopausal women deviated slightly from Hardy-Weinberg equilibrium, although these differences were not statistically significant. Previous studies have shown a range of genotype distributions. In a recent meta-analysis by $\mathrm{Ye}$ and Parry [16], the A2/A2 genotype prevalence ranged from 7.7 to $23.4 \%$ among Caucasian women in 11 different studies. This variability in estimates could be due, in part, to small sample sizes. In the present study, we found that $11 \%$ of premenopausal controls and $12 \%$ of postmenopausal controls had the A2/A2 genotype, which falls well within this range. However, the prevalence of heterozygotes was higher in our population than in other studies. It is unlikely that this could be attributed to population stratification, since western New York is a fairly homogeneous area, and women were all of European descent and, for the most part, at least second-generation or third-generation Americans. Another possible explanation for the higher proportion of heterozygotes could be genotyping errors, although two independent investigators read the gels and at least $20 \%$ of the samples were repeated for quality control. Furthermore, assays were validated by confirmation of polymorphic Mendelian inheritance patterns in seven human family cell lines $(n=134)$, each encompassing three generations.

In summary, our findings support those of several other studies that variant CYP17 alleles modify breast cancer risk associated with several hormonal and reproductive factors. These collective findings may point the way toward further investigations into the role of metabolic variability in steroidogenesis and metabolism in relation to breast cancer risk, and target women who may be most at risk for the disease.

\section{Competing interests}

None declared.

\section{References}

1. Feigelson HS, Coetzee GA, Kolonel LN, Ross RK, Henderson BE: A polymorphism in the CYP17 gene increases the risk of breast cancer. Cancer Res 1997, 57:1063-1065.

2. Weston A, Pan C-F, Bleiweiss IJ, Ksieski HB, Roy N, Maloney N Wolff M: CYP17 genotype and breast cancer risk. Cancer Epidemiol Biomarkers Prev 1998, 7:941-944. 
3. Helzlsouer KJ, Huang H-Y, Strickland PT, Hoffman S, Alberg AJ, Comstock GW, Bell DA: Association between CYP17 polymorphisms and the development of breast cancer. Cancer Epidemiol Biomarkers Prev 1998, 7:945-949.

4. Haiman CA, Hankinson SE, Spiegelman D, Colditz GA, Willett WC, Speizer FE, Kelsey KT, Hunter DJ: Relationship between a polymorphism in CYP17 with plasma hormone levels and breast cancer. Cancer Res 1999, 59:1015-1020.

5. Dunning AM, Healey CS, Pharoah PDP, Foster NA, Lipscombe JM, Redman KL, Easton DF, Day NE, Ponder BAJ: No association between a polymorphism in the steroid metabolism gene CYP17 and risk of breast cancer. Br J Cancer 1998, 77:20452047.

6. Bergman-Jungestrom $M$, Gentile $M$, Lundin A-C and the SouthEast Breast Cancer Group: Association between CYP17 gene polymorphism and risk of breast cancer in young women. Int $J$ Cancer 1999, 84:350-353.

7. Spurdle AB, Hopper JL, Dite GS, Chen X, Cui J, McCredie MR, Giles GG, Southey MC: CYP17 promoter polymorphism and breast cancer in Australian women under age forty years. $J$ Nat/ Cancer Inst 2000, 92:1674-1681.

8. Huang CS, Chern HD, Chang KJ, Cheng CW, Hsu SM, Shen CY: Breast cancer risk associated with genotype polymorphism of the estrogen-metabolizing genes CYP17, CYP1A1, and COMT: a multigenic study on cancer susceptibility. Cancer Res 1999, 59:4870-4875.

9. Mitrunen K, Jourenkova N, Kataja V, Eskelinen M, Kosma VM, Benhamou S, Vainio H, Uusitupa M, Hirvonen A: Steroid metabolism gene CYP17 polymorphism and the development of breast cancer. Cancer Epidemiol Biomarkers Prev 2000, 9:1343-1348.

10. Jernstrom H, Vesprini D, Bradlow HL, Narod SA: Re: CYP17 promoter polymorphism and breast cancer in Australian women under age forty years [letter]. J Natl Cancer Inst 2001, 93:554.

11. Kuligina ES, Togo AV, Suspitsin EN, Grigoriev MY, Pozharisskiy KM, Chagunava OL, Berstein LM, Theillet C, Hanson KP, Imyanitov EN: CYP17 polymorphism in the groups of distinct breast cancer susceptibility: comparison of patients with the bilateral disease vs. monolateral breast cancer patients vs. middleaged female controls vs. elderly tumor-free women. Cancer Lett 2000, 156:45-50.

12. Miyoshi Y, Iwao K, lkeda N, Egawa C, Noguchi S: Genetic polymorphism in CYP17 and breast cancer risk in Japanese women. Eur J Cancer 2000, 36:2375-2379.

13. Dunning AM, Healey CS, Pharaoh PDP, Teare MD, Ponder BA, Easton DF: A systematic review of genetic polymorphisms and breast cancer risk. Cancer Epidemiol Biomarkers Prev 1999, 8:843-854

14. Hamajima N, Iwata $\mathrm{H}$, Obata $\mathrm{Y}$, Matsuo $\mathrm{K}$, Mizutani M, Iwase $\mathrm{T}$, Miura S, Okuma K, Ohashi K, Tajima K: No association of the $5^{\prime}$ promoter region polymorphism of CYP17 with breast cancer risk in Japan. Jpn J Cancer Res 2000, 91:880-885.

15. Feigelson HS, Mckean-Cowdin R, Coetzee GA, Stram DO, Kolonel LN, Henderson BE: Building a multigenic model of breast cancer susceptibility: CYP17 and HSD17B1 are two important candidates. Cancer Res 2001, 61:785-789.

16. Ye Z, Parry JM: The CYP17 MspA1 polymorphism and breast cancer risk: a meta-analysis. Mutagenesis 2002, 17:119-126.

17. Omura T, Morohashi K-I: Gene regulation of steroidogenesis. $J$ Steroid Biochem Mol Biol 1995, 53:19-25.

18. Crocitto LE, Feigelson HS, Yu MC, Kolonel LN, Henderson BE, Coetzee GA: A polymorphism in intron 6 of the CYP17 gene. Clin Genet 1997, 52:68-69.

19. Carey AH, Waterworth $D$, Patel K, White D, Little J, Novell P, Franks $\mathrm{S}$, Williamson R: Polycystic ovaries and premature male pattern baldness are associated with one allele of the steroid metabolism gene CYP17. Human Mol Genet 1994, 3:1873-1876.

20. Kristensen VN, Haraldsen EK, Anderson KB, Lonning PE, Erikstein B, Karensen R, Gabrielsen OS, Borresen-Dale AL: CYP17 and breast cancer risk: the polymorphism in the $5^{\prime}$ flanking area of the gene does not influence binding to Sp-1. Cancer Res 1999, 59:2825-2828.

21. Lin CJ, Martens JW, Miller WL: NF-1C, Sp1, and Sp3 are essential for transcription of the human gene for $\mathrm{P} 450 \mathrm{c} 17$ (steroid 17 alpha-hydroxylase/17,20 lyase) in human adrenal $\mathrm{NCl}-$ H295A cells. Mol Endocrinol 2001, 15:1277-1293.

22. Feigelson HS, Shames LS, Pike MC, Coetzee GA, Stancyz FZ, Henderson BE: Cytochrome P450c17alpha gene (CYP17) polymorphism is associated with serum estrogen and progesterone concentrations. Cancer Res 1998, 58:585-587.

23. Feigelson HS, McKean-Cowdin R, Pike MC, Coetzee GA, Kolonel LN, Nomura AMY, LeMarchand L, Hendersen BE: Cytochrome $\mathrm{P} 450 \mathrm{c} 17 \alpha$ gene (CYP17) polymorphism predicts use of hormone replacement therapy. Cancer Res 1999, 59:39083910.

24. Frame LT, Ambrosone CB, Kadlubar FF, Lang NP: Host-environment interactions that affect variability in human cancer susceptibility. In Human Variability in Response to Chemical Exposures: Measures, Modeling and Risk Assessment. Edited by Neumann DA, Kimmel CA. Boca Raton: CRC Press; 1998.

25. Graham S, Hellmann R, Marshall J, Freudenheim J, Vena J, Swanson M, Zielezny M, Nemoto T, Stubbe N, Raimondo T: Nutritional epidemiology of postmenopausal breast cancer in western New York. Am J Epidemiol 1991, 134:552-566.

26. Freudenheim JL, Marshall JR, Vena JE, Laughlin R, Brasure JR, Swanson M, Nemoto T, Graham S: Premenopausal breast cancer risk and intake of vegetables, fruits, and related nutrients. J Nat/ Cancer Inst 1996, 88:340-348.

27. Ambrosone $\mathrm{CB}$, Freudenheim JL, Graham S, Marshall JR, Vena JE, Brasure JR, Michalek AM, Laughlin R, Nemoto T, Gillenwater $\mathrm{K}$, Harrington AM, Shields PG: Cigarette smoking, $\mathrm{N}$-acetyltransferase 2 genetic polymorphisms, and breast cancer risk. JAMA 1996, 276:1494-1501.

\section{Correspondence}

Christine B Ambrosone, PhD, Roswell Park Cancer Institute, Elm and Carlton Streets, Buffalo, NY 14263, USA. Tel: +1 716845 3082; fax: +1 716845 8487; e-mail: christine.ambrosone@roswellpark.org 